\title{
Correlation between the macroscopic diffusion rates and the microscopic interactions in ethylene glycol-based solvents
}

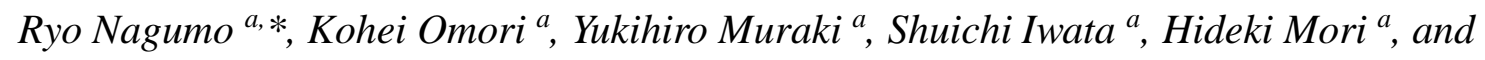
Hidetaka Yamada ${ }^{b}$

${ }^{a}$ Department of Life Science and Applied Chemistry, Nagoya Institute of Technology,

Gokiso-cho, Showa-ku, Nagoya-shi, Aichi 466-8555, Japan

${ }^{\mathrm{b}}$ Chemical Research Group, Research Institute of Innovative Technology for the Earth (RITE), 9-2 Kizugawadai Kizugawa-shi, Kyoto 619-0292, Japan 


\section{Supporting Information for Publication}

TABLE S1: Molecular weights of solvent molecules, number of solvent molecules in the simulation cells, cell lengths, simulated cell densities, and computational times for $\mathrm{CO}_{2}$-loaded solvent systems.

\begin{tabular}{|c|c|c|c|c|c|c|}
\hline $\begin{array}{l}\text { Solvent } \\
\text { molecule }\end{array}$ & $\begin{array}{c}\text { Molecular } \\
\text { weight } \\
\text { [g/mol] }\end{array}$ & $\begin{array}{c}\text { Number of } \\
\text { solvent } \\
\text { molecules }\end{array}$ & $\begin{array}{l}\text { Number of } \\
\qquad \mathrm{CO}_{2} \\
\text { molecules }\end{array}$ & $\begin{array}{l}\text { Cubic dimensions } \\
\qquad[\mathrm{nm}]\end{array}$ & $\begin{array}{l}\text { Simulated } \\
\text { cell density } \\
{\left[\mathrm{g} / \mathrm{cm}^{3}\right]}\end{array}$ & $\begin{array}{l}\text { Computational } \\
\text { time [ns] }\end{array}$ \\
\hline EG & 62.07 & 1800 & 41 & $5.52 \times 5.52 \times 5.52$ & 1.12 & 20 \\
\hline diEG & 106.1 & 1040 & 38 & $5.47 \times 5.47 \times 5.47$ & 1.14 & 20 \\
\hline triEG & 150.2 & 750 & 41 & $5.48 \times 5.49 \times 5.49$ & 1.15 & 20 \\
\hline tetraEG & 194.2 & 580 & 35 & $5.47 \times 5.47 \times 5.47$ & 1.16 & 50 \\
\hline hexaEG & 282.3 & 400 & 37 & $5.48 \times 5.49 \times 5.48$ & 1.15 & 50 \\
\hline diglyme & 134.2 & 750 & 17 & $5.53 \times 5.53 \times 5.53$ & 0.994 & 20 \\
\hline triglyme & 178.2 & 1650 & 48 & $7.80 \times 7.80 \times 7.80$ & 1.04 & 50 \\
\hline tetraglyme & 222.3 & 1365 & 33 & $7.82 \times 7.82 \times 7.82$ & 1.06 & 20 \\
\hline EG-imi & 126.2 & 2520 & 33 & $7.88 \times 7.88 \times 7.88$ & 1.08 & 20 \\
\hline diEG-imi & 170.2 & 600 & 11 & $5.36 \times 5.36 \times 5.37$ & 1.10 & 20 \\
\hline triEG-imi & 214.3 & 450 & 10 & $5.23 \times 5.23 \times 5.23$ & 1.12 & 20 \\
\hline
\end{tabular}




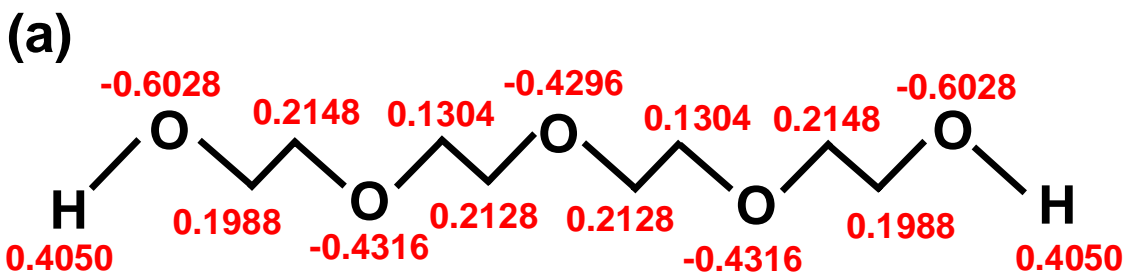

(b)
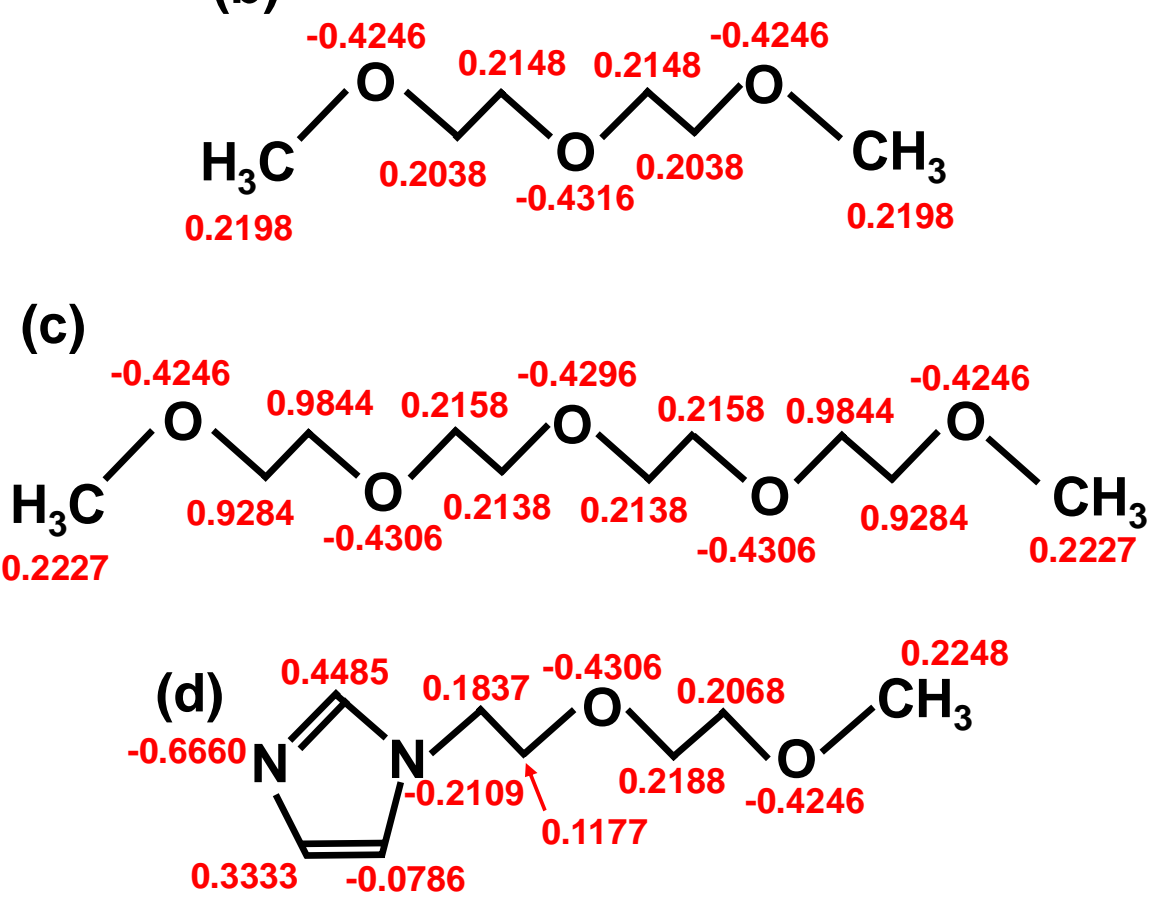

Figure S1. Partial charges of (a) tetraEG, (b) diglyme, (c) tetraglyme, and (d) diEG-imi in the $\mathrm{CO}_{2}$-loaded solvent systems. 

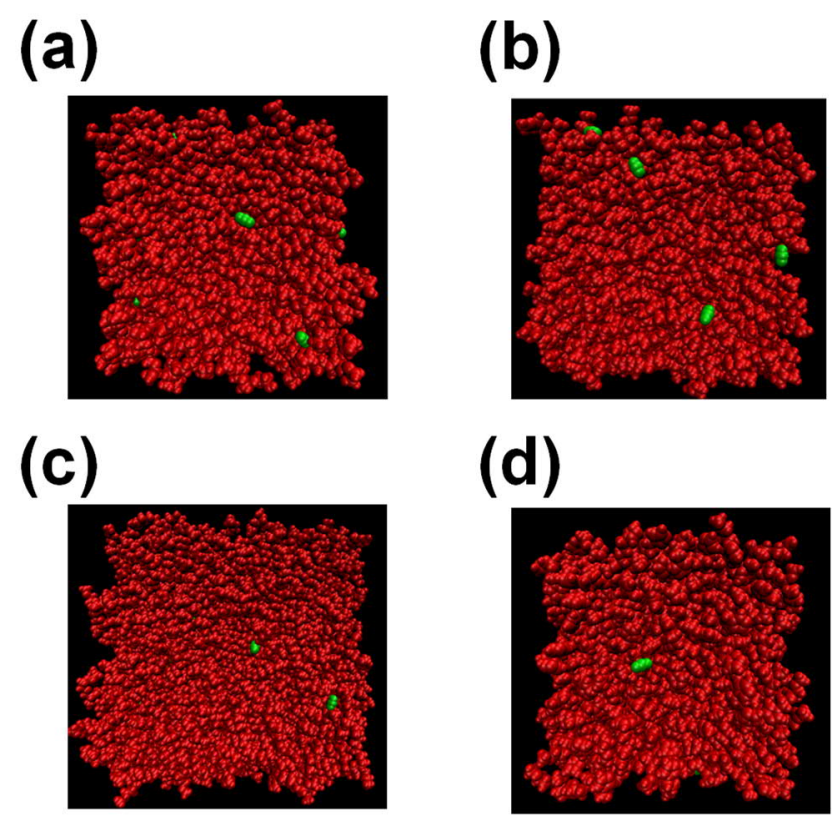

(d)

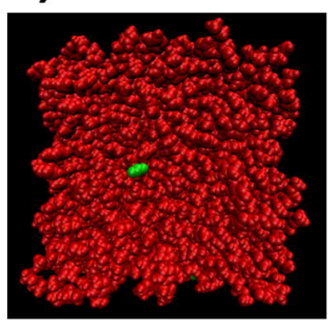

Figure S2. Snapshots of the simulation cells of (a) tetraEG, (b) diglyme, (c) tetraglyme, and (d) diEG-imi for the $\mathrm{CO}_{2}$-loaded solvent systems after $20 \mathrm{~ns}$ of the MD simulations with the NVT ensemble. Color code: green, $\mathrm{CO}_{2}$ molecule; red, solvent molecule. 


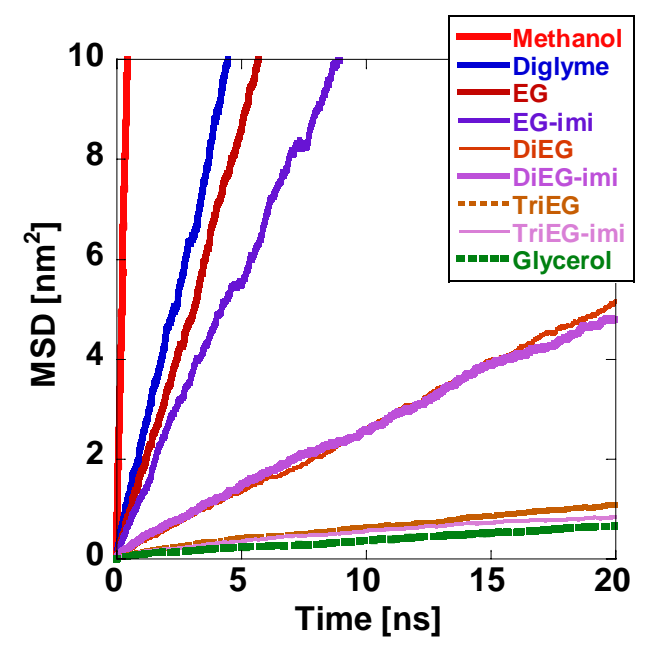

Figure S3. Elapsed time dependence of mean square displacements of the solvent molecules for pure solvent systems.

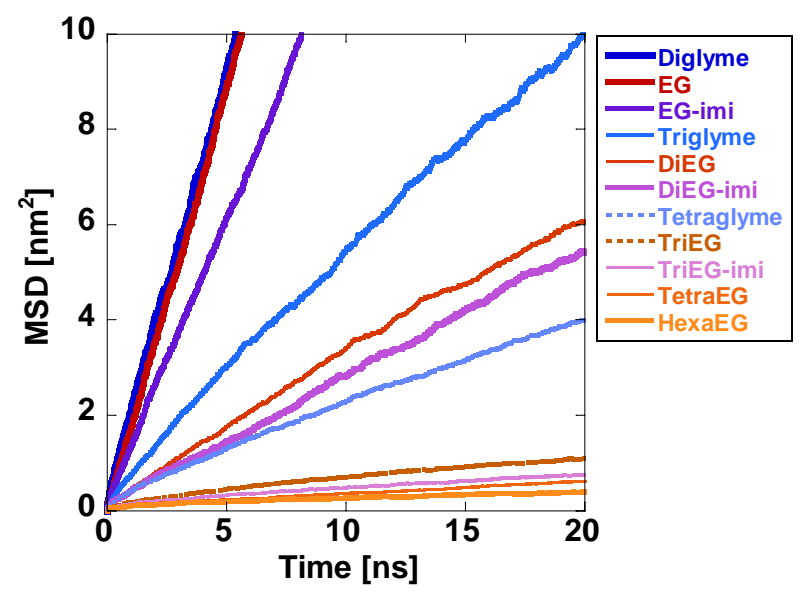

Figure S4. Elapsed time dependence of MSDs of the solvent molecules for $\mathrm{CO}_{2}$-loaded solvent systems. 


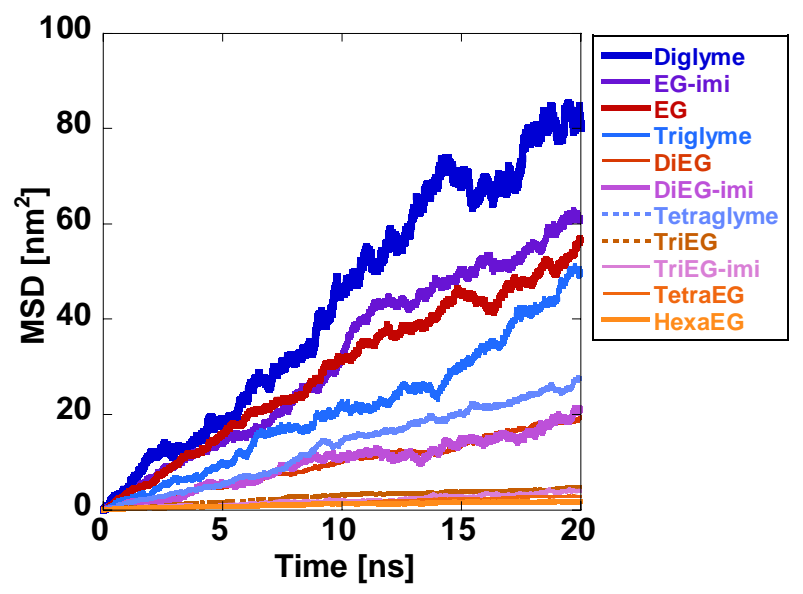

Figure S5. Elapsed time dependence of MSDs of the $\mathrm{CO}_{2}$ molecules for $\mathrm{CO}_{2}$-loaded solvent systems. 